\title{
MARCO CONTEXTUAL DEMOGRÁFICO DE LA EDUCACIÓN SUPERIOR EN HONDURAS
}

\author{
Manuel Antonio Flores Fonseca, Universidad Nacional Autónoma de Honduras, \\ Instituto de Investigaciones Económicas y Sociales (IIES UNAH), \\ Ciudad universitaria edifico c2 primer piso. Tel./Fax: 504-22348973 \\ Correo electrónico: mflores@iies-unah.org
}

\section{RESUMEN}

Este trabajo tiene por objetivo brindar un panorama general del comportamiento de la dinámica demográfica, tanto al pasado, presente y el futuro. Describe los cambios generales de la población enmarcados en la teoría de la transición demográfica y su impacto en la estructura por edades de la población, lo que llevará a cambios espectaculares que se magnifican en el umbral del bono demográfico. Este fenómeno es un elemento de vital importancia que se convierte en la contribución de la demografía a la economía. En los próximos años provocará un aumento en el flujo de personas en edad de trabajar como nunca en la historia del país y al mismo tiempo permitirá que las tasas de dependencia demográfica desciendan a valores muy bajos, y aprovechando esa situación con acciones anticipadas de política pública, se pueden producir beneficios económicos.

Qué decir de los cambios demográficos que también se producen en grupos esE\&A IIES peciales, tanto de la salud y la educación, que llevará a cambiar el flujo de recursos financieros a grupos prioritarios, que no necesariamente son los mismos que se priorizan actualmente. Dentro de los grupos especiales en educación, está la población en edad de educación terciaria que alcanzará números efectivos teóricos elevados en las próximas décadas que demandarán los servicios de educación.

Palabras clave: Educación Superior, Aspectos Demográficos, Demografía. 


\title{
DEMOGRAPHIC CONTEXTUAL FRAME- WORK OF HIGHER EDUCATION IN HONDURAS
}

\author{
Manuel Antonio Flores Fonseca, Universidad Nacional Autónoma de Honduras, \\ Instituto de Investigaciones Económicas y Sociales (IIES UNAH), \\ Ciudad universitaria edifico c2 primer piso. Tel./Fax: 504-22348973 \\ Correo electrónico: mflores@iies-unah.org
}

E\&A IIES

\section{ABSTRACT}

The main objective of this report is to make a general overview of the behavior of demography dynamics, which includes past, present, and future. It describes the general changes of population included in demographic transition theory and its impact on the population's age structure, which will lead to sudden changes magnified in the threshold of demographic bonus.

This phenomenon is an element of vital importance in that it becomes demography's contribution to the economy. In the following years it will start an increase of people in age of employment unlike any other in this country and it will decrease the demographic dependency rates to very low values as well. Taking advantage of this situation with quick actions of public politics, profit can be made out of it.

In the matter of demographic changes within special groups, being the health or the education sectors, the flow of financial resources will shift to different groups that at present are not as prioritized. Within groups pertaining to education, the population with age of tertiary education will rise to elevated effective numbers in the next decades that will demand on educational services.

Keywords: Higher education, Demographic aspects, Demography. 


\section{INTRODUCCIÓN}

Con el recuento histórico de las principales variables demográficas, su actualidad y las principales tendencias que se avizoran para el futuro pretendemos dar un panorama general de la dinámica demográfica hondureña.

Esto para observar como los cambios principalmente en la mortalidad y la fecundidad en una manera no sincronizada han llevado al crecimiento acelerado de la población, que se manifiesta en grandes volúmenes de personas que se agregan a la población y que continuarán sumándose de manera inercial, aunque el crecimiento disminuya. Esta manifestación ha sido la principal preocupación de autoridades, e incluso de la sociedad en general, desde el punto de vista demográfico, sin embargo, los cambios que se producen en la estructura por edad de la población, deben ser sin duda una preocupación y más que todo de preparación de políticas y acciones públicas y privadas que lleven al aprovechamiento del bono demográfico, que es periodo de varios años donde las relaciones de dependencia demográfica caen a bajos niveles y esto significa que las inversiones en algunos grupos de población deben de reencausarse o transferirse a otros grupos. En estos cambios de estructura puede ser visible el gran volumen de la población en edad de trabajar, principalmente la económicamente activa que además de requerir empleo, necesita capacitación, formación y que los actores económicos hagan inversión. Al mismo cuando la masa laboral está ocupada, genera mayores ingresos que se traducen entre otras cosas en tributos y en consumo que hace crecer la economía del país.

Otra manifestación de los cambios demográficos muy ligada a la fuerza laboral es la población objetivo de la educación, principalmente en la edad de estudiar el nivel medio y el terciario. En el caso del nivel terciario la población en edad de estudiar tiene una tendencia incremental desde los años cincuenta del siglo pasado, pero es hasta fines de la década del treinta del presente siglo donde puede alcanzar su cúspide, para emprender su descenso, por lo que en los próximos veinticinco años los flujos de población en edad de estudiar en la educación superior pueden ser los más grandes en historia demográfica en Honduras. Dentro de esta se encuentra la población que ha estado estudiando en los centros de educación superior en el país, misma que ha tenido una cobertura muy pobre y que posiblemente se incrementará a través del tiempo por los flujos de entrada, por la oferta académica, las posibilidades de continuar estudios y por las percepciones que se tengan de la tasa de retorno de estudiar en la educación superior.

Al final, vemos como las poblaciones objetivo teóricas de la educación superior en su distribución geográfica nacional utilizando la regionalización educativa de la Universidad Nacional Autónoma de Honduras (UNAH) se advierte la supremacía de las redes más desarrolladas, más urbanizadas y donde la 
cobertura educativa es más alta, lo que ha producido una concentración de la educación superior en detrimento de las demás regiones del país.

\section{OBJETIVO DEL TRABAJO}

El objetivo de esta investigación es mostrar como los cambios demográficos que se producen a nivel de país influyen en las sub-poblaciones entre ellas aquellas que son objetivos de la educación, dentro de la cuales se encuentra la de educación superior, que ubica a los efectivos teóricos que deben estar en ese nivel terciario a nivel nacional, municipal y a nivel de desagregación por redes educativas de la UNAH.

\section{ASPECTOS METODOLÓGICOS}

Las principales fuentes de información de este trabajo de investigación incluyen las estimaciones de los principales indicadores demográficos de diversas fuentes sólidas de información, tal es el caso de los censos y las encuestas demográficas del país, elaboradas por la Dirección de Estadísticas y Censos de Honduras (DGECH) y el Instituto de Estadística (INE). Otras fuentes de datos están conformadas por las estimaciones y proyecciones de población realizadas por el Centro Latinoamericano de Demografía (CELADE) y por el INE.

E\&A IIES

La metodología utilizada en este trabajo es descriptiva, se parte de construir la evolución de los principales indicadores demográficos y de las series a futuro utilizando la información contenida en las fuentes de datos secundarias. Con estos indicadores se conocen las principales tendencias del pasado, presente y futuro y se plantean el análisis respectivo de los comportamientos relativos a la población teórica de la educación superior.

\section{RESULTADOS}

\subsection{Comportamiento de las variables demográficas.}

La Tasa Bruta de Natalidad (TBN) ${ }^{1} /$ estimada con datos de la Encuesta Nacional de Demografía y Salud 2005-2006 (ENDESA, 2005-2006) se situaba en 26.7 por mil habitantes. Existen diferencias según el lugar de residencia, en el área urbana la TBN se situaba en 24.3 y en el área rural el valor de este indicador alcanzaba 28.9 por mil habitantes.

La Tasa Global de Fecundidad (TGF) ${ }^{2} /$ estimada en la ENDESA 2005-2006 es de 3.3 hijos por mujer, teniendo un descenso significativo al compararla con 
la estimada en la Encuesta Nacional de Epidemiología y Salud Familiar 2001 (ENESF-2001) que fue de 4.4 hijos por mujer. Los resultados de todas las encuestas de epidemiología y afines ${ }^{3} /$ del país muestran un lento descenso de 2.04 hijos en aproximadamente veinte años (1981-2001), sin embargo, en los últimos años el descenso ha significado 1.1 hijos por mujer. Esta tasa vista desde una perspectiva de largo plazo muestra como en los años cincuenta su nivel era de 7.5 hijos por mujer, en los años ochenta bajaba a 6 hijos y en 1990 era de 4.3 hijos por mujer. En el quinquenio actual de 2010 a 2015 su valor es estimado en 2.9 hijos y se proyecta que alcanzará el nivel de reemplazo en el quinquenio 2030-2035, para ubicarse en 1.8 hijos en el año 2050.

En el uso de métodos anticonceptivos alrededor de dos tercios de las mujeres en unión de 15 a 49 años de edad en el momento de la encuesta se encontraba usando algún método de planificación familiar (INE, 2006).

Aunque el país ha logrado descensos significativos en los indicadores de la mortalidad, al mismo tiempo producto de la transición epidemiológica y de los cambios en los estilos de vida, principalmente de alimentación, están surgiendo una gama de enfermedades que implican grandes costos en la salud pública, tal es el caso de la enfermedades de la diabetes, cardiovasculares, accidentes cerebrales vasculares y se agrega el cáncer.

En la Tasa Bruta de Mortalidad (TBM $)^{4} /$ se puede evidenciar el descenso de la mortalidad general. Este indicador en los años cincuenta alcanzaba valores altos de 24.6 defunciones por mil habitantes, en el quinquenio 1985-1990 dicho valor era de 7.3 defunciones por mil habitantes y para el quinquenio 2010-2015 llega a niveles de 4.9 muertes por mil.

Con datos actualizados de CELADE se observa los descensos en la mortalidad infantil en el periodo 1950 al 2050. Los niveles actuales del quinquenio 20102015 sitúan a la Tasa de Mortalidad Infantil (TMI) 5 /en el valor de 24.9 muertes por mil, que aunque estos niveles son todavía altos comparados con los países de la región y se precisan grandes esfuerzos para reducirlos.

Una medida demográfica que refleja mejor el nivel de la mortalidad del país es la esperanza de vida $\left(\mathrm{e}^{\circ}\right)$, este indicador estimaba con datos censales del 2001 en 70 años, 72 para mujeres y 68 para hombres. Las ganancias de años en la esperanza de vida de Honduras han sido muy grandes, CELADE estima valores de 42 años en 1950, aumentaron en diez años a 48 años, llegaron a 68 años 
en 1990 y en el quinquenio 2010-2015 alcanzan 73.1 años en total y una significativa diferencia por sexo de 70.7 para hombres y 75.6 para mujeres.

Otra variable demográfica importante es la migración ya que ésta mide los movimientos de la población que rebasan una frontera geográfica específica para adoptar residencia. La interna mide los desplazamientos dentro del país y la internacional fuera del país.

Existen estimaciones de migración interna a nivel de División Administrativa Mayor (DAM) que han encontrado que la proporción de migrantes internos absolutos residente en un departamento diferente al de su nacimiento fue de un continuo aumento entre 1950 y 1974, cambiando esta tendencia al descenso desde ese año y en el 2001 se estima que esta proporción alcanzaba el 17.2\%. A nivel de División Administrativa Menor (DAME) la migración interna de toda la vida ha aumentado en términos absolutos entre el período 1988 - 2001 en más de un cuarto del millón de personas, sin embargo, en términos relativos ha significado una reducción de un cuatro por ciento, de $27.5 \%$ a $23.3 \%$ (Flores, 2009).

E\&A IIES

La migración interna reciente a nivel de DAM en Honduras en las últimas tres décadas tiene la tendencia a la disminución de su proporción. Lo mismo sucede con su intensidad a nivel de DAME que aunque aumentó en términos absolutos entre las mediciones del período 1988 - 1983 y 2001 - 1996 en más de ochenta mil personas, en términos relativos ha significado una reducción de uno y medio por ciento del $13.7 \%$ a $12.1 \%$.

El proceso migratorio hondureño está asociado a la estructuración de la infraestructura socio productiva del país, donde fenómenos como la ampliación de la frontera agrícola, la ampliación de la red vial, la conformación de ciudades intermedias y el fortalecimiento de una urbanización bipolar (Tegucigalpa y San Pedro Sula) ha influido para tener un patrón migratorio hacia el corredor central y una primacía de la zona norte.

En el país los flujos migratorios han tenido variaciones en términos absolutos y relativos, de acuerdo a los dos últimos registros censales (1988 y 2001) han aumentado las DAM y las DAME con saldo migratorio negativo, tanto en la migración de toda la vida, como en la reciente, esto demuestra mayor concentración en los flujos migratorios internos. 
Los principales flujos migratorios de toda la vida a nivel de DAME que son mayores de dos mil personas en el 2001 se produjeron principalmente hacia Tegucigalpa, San Pedro Sula y otras ciudades intermedias como Choloma, Villanueva, La Lima, La Ceiba, El Progreso y Puerto Cortés. En la migración reciente se repite el mismo patrón de flujos hacia los mismos lugares.

En el caso de la migración internacional, Honduras no ha sido un país muy atractivo para inmigrar, esto se demuestra porque el porcentaje de extranjeros en el país nunca ha superado el cinco por ciento de la población total. En los años setenta y ochenta los conflictos armados en la región centroamericana generaron un flujo importante de personas de los países vecinos, que en su mayoría fueron asentados en campos de refugiados con status especial.

En la emigración, encontramos como la experiencia hondureña se remonta desde la Costa Norte del país, tanto por sectores étnicos alrededor de la población garífuna y las conexiones con los Estados Unidos de América derivadas del enclave bananero. Esto sugiere que antes de los masivos desplazamientos de la región centroamericana hacia Estados Unidos, los hondureños se ubicaron en primer lugar hacia ese destino alrededor de los años setenta, sin embargo, en los ochenta fueron desplazados al último lugar por los emigrantes de los países vecinos y llevando a la actualidad a ocupar el tercer lugar en ese destino (Baumeister, 2010).

Las características de las personas de origen hondureño en los Estados Unidos según la Encuesta de la Comunidad Americana (ACS) del 2009 indica: un volumen de 625,000 personas, alcanzando el octavo lugar de la población de origen hispano, siete de cada diez habían nacido en el extranjero, el $78 \%$ había llegado a partir de 1990, solo el $20 \%$ son ciudadanos estadounidenses, el $40 \%$ habla inglés con soltura, una edad mediana de 28 años, la mitad de los mayores de 25 años no ha obtenido un diploma de secundaria, el $61 \%$ vive en el sur, principalmente en Florida y Texas, $27 \%$ viven en la pobreza, más de la mitad no tiene seguro de salud, la tasa de propiedad de vivienda es apenas del $32 \%$ (Pew Hispanic Center, 2011).

En el censo de población de los Estados Unidos de América del año 2010 empadronó un total de 633,401 personas de origen hondureño, con una tasa de incremento muy elevada dentro de los hispanos (Ennis, Sharon R. y otros, 2011). Por lo tanto el principal destino de los emigrantes hondureños es Estados Unidos y en menor medida España, México, otros países de Centroamérica 
y el mundo. En España hay un total de 32,418 hondureños, de los cuales 9,392 son hombres y 23,026 son mujeres según avance del Padrón Español al 1 de enero 2011 (INE, 2011).

La emigración hondureña ha alcanzado dimensiones de importancia y si bien ha producido un gran flujo de remesas (convertida en una de las principales fuentes de divisas del país, 2800 millones de dólares en el 2008). Incluso ha alcanzado una de las proporciones más altas con respecto al PIB (19\%) a nivel mundial (Ratha y otros, 2011).

\subsection{Descensos de la Mortalidad y la Fecundidad.}

La visualización de la transición demográfica de Honduras se percibe por la reducción de la mortalidad antes que la fecundidad. Este descenso de la mortalidad se derivó de mejoras en las sistemas de salud, creación de infraestructura hospitalaria, introducción de medicamentos de bajo costo, antibióticos, vacunas, que posibilitaron mejores condiciones sanitarias, e incluso condujeron a que muchos embarazos llegaran a término y sobrevivieran más niños y madres.

El descenso de la fecundidad fue posterior al de la mortalidad y su velocidad ha sido más lenta, porque el acceso a los mecanismos de descenso fue posterior a los mecanismos por preservar la vida. En el descenso de la fecundidad en América Latina y por ende en Honduras ha influido la expansión de la preferencia por proles más pequeñas, que ha creado mecanismos que hacen desventajosas las proles numerosas, entre ellos el acceso a la escuela, canales simbólicos y la diseminación de los medios de comunicación, así como el acceso a la actividad laboral de las mujeres, que han idealizado a la familia pequeña como signo de bienestar. Esta preferencia se materializó con la "revolución anticonceptiva", cuyos pilares fueron de carácter biotecnológicos, políticos y culturales que se combinaron y llevaron a los anticonceptivos a mejoras en la prevalencia, fuentes de obtención y gama de métodos (CELADE 2005).

El descenso de la mortalidad venía disminuyendo muy lentamente desde los años treinta, pero desde los años cincuenta y sesenta este proceso se fue haciendo más notorio, en cambio en la fecundidad la reducción se hizo más evidente desde los años setenta. La diferencia entre la mortalidad y la fecundidad produjo tasas de crecimiento natural superiores al tres por ciento entre los años 
cincuenta hasta los años noventa, manifestando sus mayores valores en los años sesenta y setenta.

Las tasas brutas de natalidad en los próximos cincuenta años continuaran descendiendo desde 25.4 por mil en el quinquenio 2010-2015 hasta valores de 13.4 por mil en el quinquenio 2045-2050, mientras tanto en las tasas brutas de mortalidad se proyecta leves descensos desde el presente quinquenio hasta el 2020-2025 cuando empezarán a aumentar producto del cambio de estructura por edades de la población (Gráfico No.1).

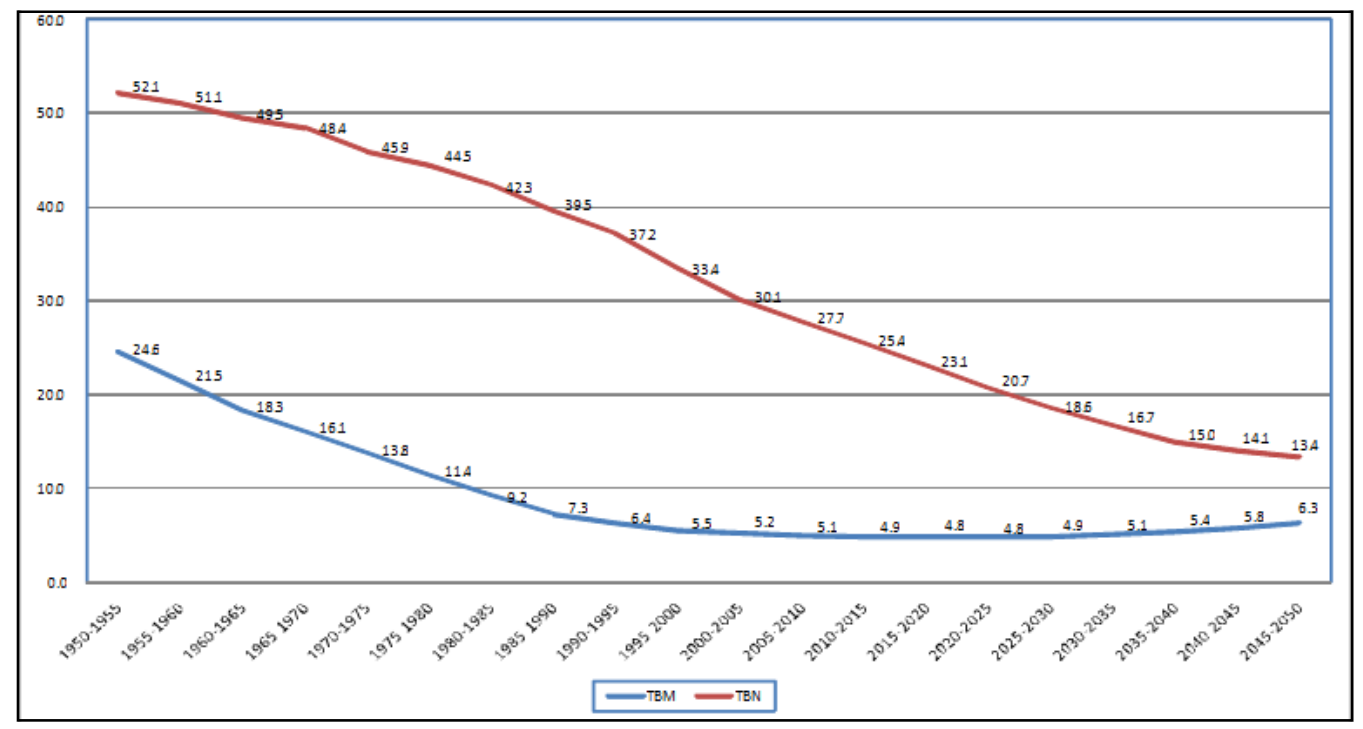

E\&A IIES

Gráfico 1, Honduras: Tasas Brutas de Mortalidad y Natalidad, 1950-2050

(Fuente: Elaboración propia en base a datos de CELADE)

\subsection{Crecimiento de la población.}

En realidad el comportamiento demográfico hondureño no es casualidad aislada del contexto de los demás países, ya que las mejoras en los condiciones sanitarias produjeron que las condiciones epidemiológicas cambiaran, provocando un descenso de la mortalidad y generando al mismo tiempo un descenso tardío de la fecundidad, que se ha traducido en la ampliación de la brecha entre ambas variables demográficas, donde la migración internacional no ha jugado un papel decisorio, una de las manifestaciones de esta situación ha sido el crecimiento acelerado de la población. 
A partir de la segunda mitad del siglo XX, el país ha producido tasas de crecimiento demográfico total superiores al tres por ciento. Para el período intercensal 1974-1988 se registró una tasa de 3.3\% mientras que para el período 1988-2001 se estima la misma en $2.7 \%$, considerada todavía como una de las más elevadas en el contexto latinoamericano, con una tendencia hacia el descenso al igual que los países de la región.

Aunque este cambio demográfico en el caso de Honduras es tardío todavía el efecto más palpable se manifiesta en el crecimiento demográfico inercial, que incide en las demandas de salud, de educación, de empleo, de vivienda y de servicios públicos, sin embargo, con los descensos en las tasas de fecundidad y de la mortalidad y por ende en la tasa de crecimiento también se han producido y producirán cambios en la estructura por edades de la población que vislumbra un panorama diferente que implica cambios en las políticas públicas.

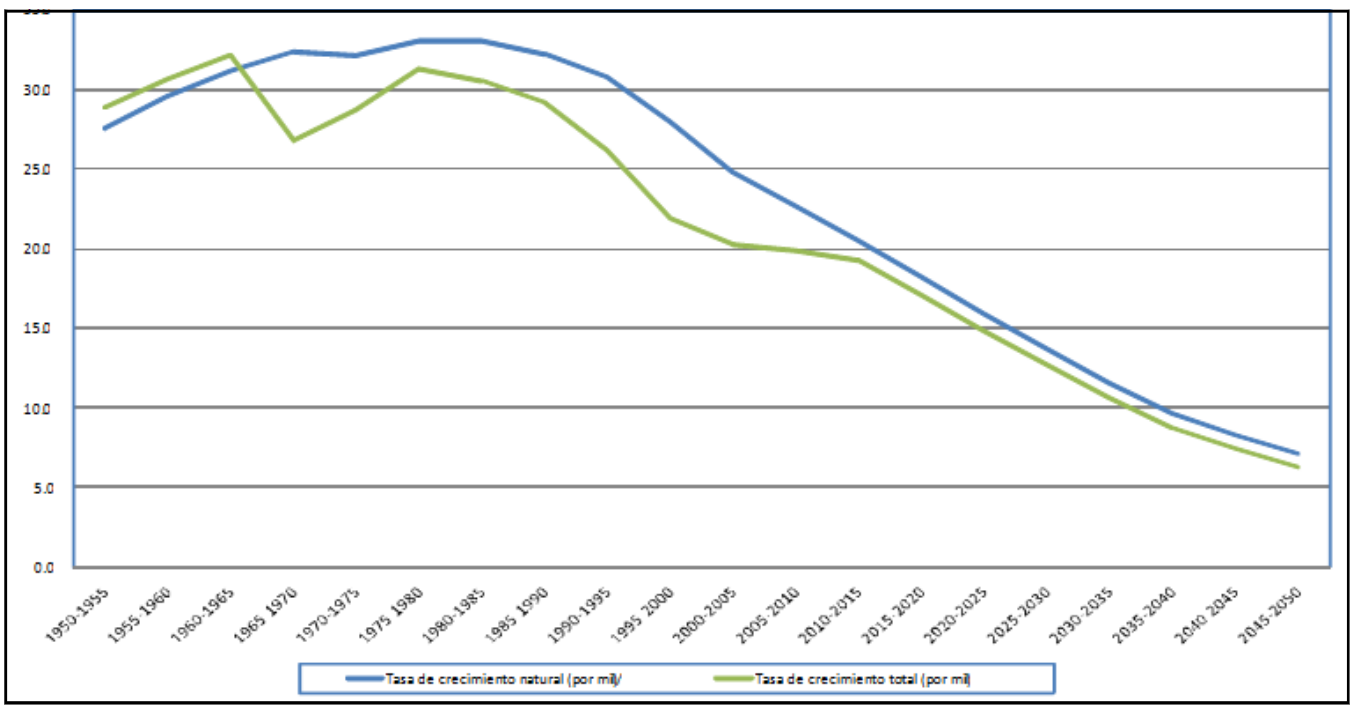

Gráfico 2, Honduras: Tasas de Crecimiento Natural y Total, 1950-2050

(Fuente: Elaboración propia en base a datos de CELADE)

En el quinquenio 2010-2015 la tasa de crecimiento total de la población hondureña se estima en $1.93 \%$, con la tendencia al descenso que hará que en los próximas tres décadas años llegue a valores menores del uno por ciento (Gráfico No.2). 
En términos absolutos el crecimiento hondureño todavía se debe a la diferencia entre los nacimientos y las defunciones, ya que el saldo migratorio aunque importante no ha tenido un papel decisorio. El número de nacimientos hondureños en los últimos quinquenios crece poco y actualmente está en su cúspide desde la cual empezará su descenso, en cambio las defunciones tienen en el futuro una tendencia incremental, a los que se suma el cambio de estructura por edades de la población.

\subsection{Cambios en la Estructura por Edades de la Población.}

La estructura por edad del país ha experimentado cambios en el pasado que hemos observado actualmente y para el futuro se esperan espectaculares cambios que hará que se prevean acciones para atender esas modificaciones.

La composición por edad de la población hondureña continúa teniendo una estructura Joven, porque todavía la proporción de población en edades de la niñez y juventud es alta. Sin embargo, las estimaciones de población para la mitad de la presente centuria muestran cambios significativos en la estructura por edad, donde las edades de la niñez cederán su peso significativo a las edades de la juventud, adultos y viejos.

Las pirámides de la población nacionales muestran más claramente los cambios en la estructura por edades. Estas han presentado formas expansivas con bases anchas para el pasado, donde se reflejan los procesos de ampliación y reducción de las bases, producto primero de la alta fecundidad, después de ampliación de la brecha con la reducción de la mortalidad, que incluso produjo más nacimientos y aumentó la proporción en las primeras edades que rejuveneció la población entre los años cincuenta y sesenta, y finalmente se nota la reducción de la fecundidad que llevó a reducciones de las proporciones de la base, desde los años setenta. Esto se observa en las pirámides de población de 1950 a 1990. Proyectando las pirámides de la población del futuro tendrán formas constrictivas, producto de las reducciones en las bases por la continua disminución de la fecundidad. Asimismo las cúspides se ampliarán por el envejecimiento de la población, reflejo de aumento en la esperanzas de vida de las personas (Flores, 2007).

Este proceso paulatino hará que la proporción de las poblaciones de edades menores de quince años se reduzcan espectacularmente. En las edades productivas también se notará la reducción en los próximos veinte años, principalmente en las personas jóvenes hasta los treinta años, consecuentemente también se producirá una reducción en los años siguientes en personas en edades menores de 
cuarenta años. En los próximos veinte años será notorio un aumento en la proporción de las poblaciones de todas las edades mayores de los treinta años y será mucho más evidente principalmente en el 2040 y 2050.

En las pirámides de población también se manifiesta el envejecimiento de la población como proceso inexorable que está viviendo la población mundial y que se está manifestando en la región y en Honduras, aunque a una menor velocidad, muestra de ello es el aumento en la proporción de poblaciones mayores de los sesenta y cinco años a través del tiempo. En el año 2010 dicha proporción alcanzará el $4.3 \%$, en el año 2030 llegará a un $6.7 \%$ y en el año 2050 se incrementará hasta el $12.5 \%$ (Gráfico No.3).

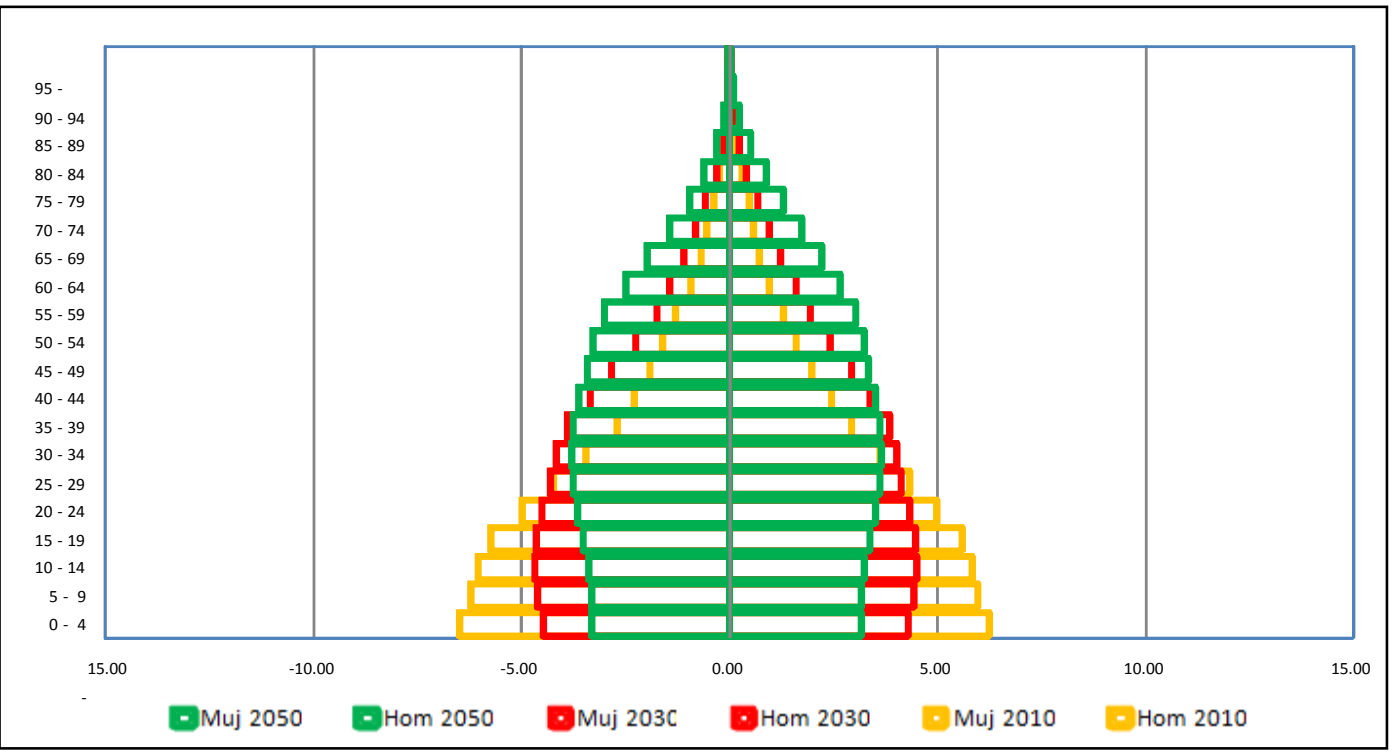

Gráfico 3 Honduras Pirámide de Población 2010, 2030, 2050

(Fuente: Elaboración propia en base a datos de CELADE)

\subsection{Cambios en la Estructura por Grandes Grupos de Edades.}

La estructura por edad de la población clasificada por grandes grupos muestra los cambios en tres subpoblaciones de interés demográfico; la integrada por los menores de quince años, las poblaciones en edad de trabajar de quince a sesenta y cuatro años y la población mayor de sesenta y cuatro años. La primera y la tercera son poblaciones dependientes y la segunda es la proveedora, que son la materia prima para estimar las relaciones de dependencia demográfica y el índice de envejecimiento.

En términos absolutos, en el país todas esas sub poblaciones incrementan sus volúmenes en general entre los años 1950 al 2050, sin embargo, la población 
menor de quince años lo hará hasta el 2020 cuando en adelante empezará la tendencia a descender en efectivos. La población en edades productivas se convierte en el subgrupo más importante de los tres ya que incrementará espectacularmente su número, de 4,488,983 en el año 2010, aumentará en veinte años a 6,948,572 y llegará en el año 2050 a 8,400,800 personas (Gráfico No.4).

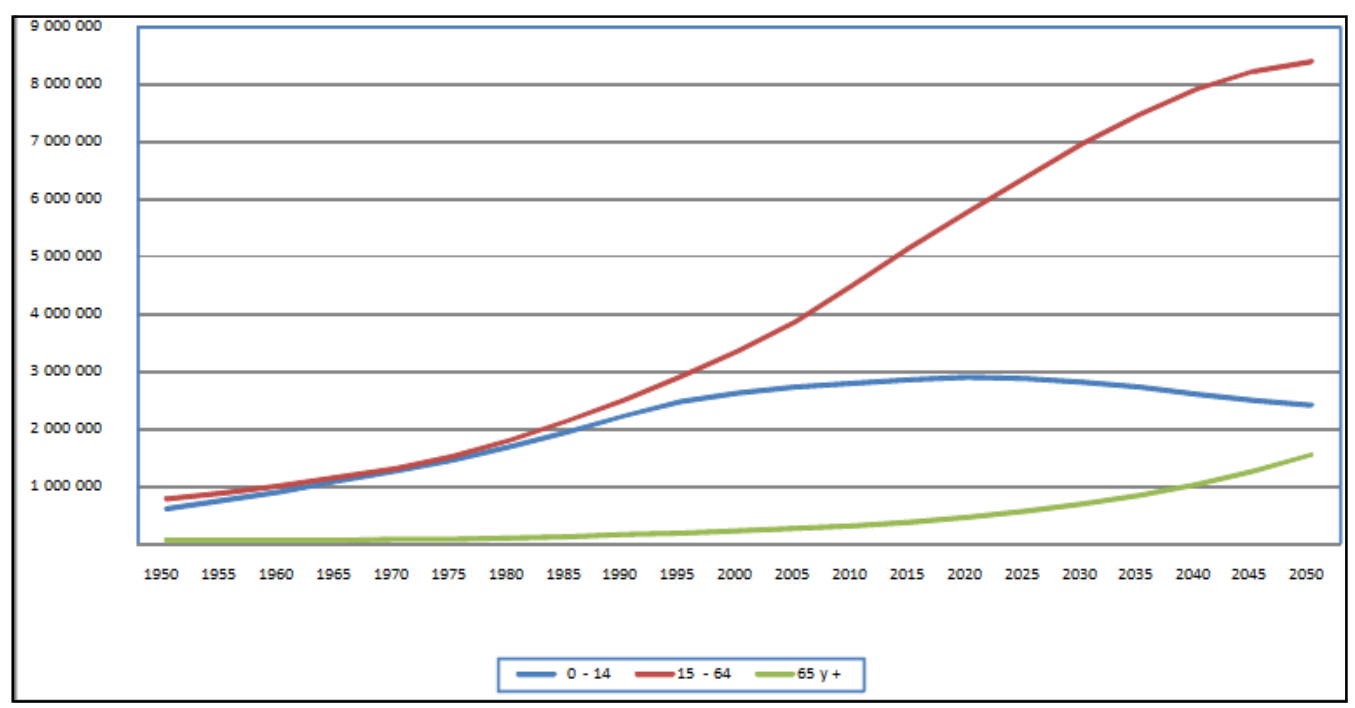

\section{Gráfico 4, Honduras, Población Según Grandes Grupos de Edad, 1950- 2050.}

(Fuente: Elaboración propia en base a datos de CELADE)

La población menor de quince años tenía una tendencia al incremento en su peso en el total de la población desde 1950 hasta 1970, cuando se revirtió esa tendencia al descenso que se mantiene desde ese año y se mantendrá en el futuro.

La subpoblación en edades productivas (15-64 años) se convierte desde los años cincuenta en el grupo que más peso tiene en la población total, actualmente representa un 58.9\% y en el año 2050 más de dos tercios de la población total pertenecerá a ese segmento, siendo el grupo donde se localizan los mayores niveles de producción económica.

La población de edades avanzadas de 65 años actualmente alcanza el $4.3 \%$ y continuará aumentando su peso en el total de la población, tal es el caso que en el año 2050 alcanzará el $12.5 \%$, es la muestra del proceso de envejecimiento de la población. 


\subsection{Bono Demográfico}

El término bono demográfico ha sido señalado para describir el estado de la transición que alude a las posibilidades que se presentan por el aumento en la tasa de crecimiento económico per cápita y en el estándar de vida. Aunque los beneficios de este período de tiempo se enfocan en la contribución de un estado de transición demográfica en el crecimiento económico, la ubicación del bono demográfico parte de supuestos más estrictamente demográficos, como son la interacción de los cambios en las relaciones de dependencia, descenso de la fecundidad y los nacimientos y cúspide de poblaciones en edad de trabajar.

En Honduras la relaciones de dependencia total $(\mathrm{RDT})^{6} /$ y la relaciones de dependencia de la niñez $(\mathrm{RDN})^{7} /$ han tenido un comportamiento muy similar a través del tiempo, ambas aumentaron desde los años 1950 hasta 1970, a partir de ese año han tenido un descenso sostenido y paralelo hasta el 2015, que continuará descendiendo pero donde se ampliará la brecha entre ambas ya que la RDT a partir del 2040 tenderá al aumento, mientras las RDN seguirán descendiendo. La relación de dependencia de la vejez $(\mathrm{RDV})^{8} /$ tiene una tendencia creciente desde los años cincuenta y continuará en todo el período.

E\&A IIES

En el quinquenio actual la RDT (que incorpora la carga demográfica de niños y viejos) es de 69.8 por cien que significa que de cada cien personas en edades productivas 70 son personas en edades dependientes. Alcanzará su valor más bajo en el período en el periodo 2040-2045 cuando descienda a 46.1 por cien. Presenta un panorama positivo en las próximas décadas porque la carga demográfica desciende a valores nunca observados en la historia demográfica del país haciendo que las poblaciones productivas sostengan menos dependientes, esta es una ventana demográfica de oportunidades.

A medida que pasa el tiempo el país se adentrará en las etapas avanzadas de la transición demográfica, donde disminuye la tasa de crecimiento y la estructura de la población se ve transformada, de pirámides de población expansivas pasa a formas constrictivas, y que desde luego vislumbra cambios significativos que desde lo demográfico tienen un impacto en la economía, ya que el comportamiento económico de las personas varía según la edad en la que se encuentren.

En estos cambios de estructura por edad de la población cuando existe una relación más favorable entre la población en edades dependientes y la población en edades productivas se produce el bono demográfico, que es un período de varias décadas que sumando al estímulo de políticas y acciones en capital 
humano, generación de empleo, ahorro e inversión se convierten en nuevas oportunidades para las poblaciones.

Con los datos del CELADE se ha estimado para Honduras que el umbral del bono demográfico se ubicará plenamente entre el año 2020 al 2045, esto porque en ese período tendrá relaciones de dependencia totales cercanas o inferiores a 60 potencialmente inactivos por cien potencialmente activos $\%$, que sería el inicio. Al mismo tiempo se está llegando a la cúspide del número de nacimientos, que son los nuevos ingresos de la población. Al final de la ventana la relación de dependencia obtendría su menor valor y el porcentaje de población en edades productivas alcanzará su mayor valor (Gráfico No.5).

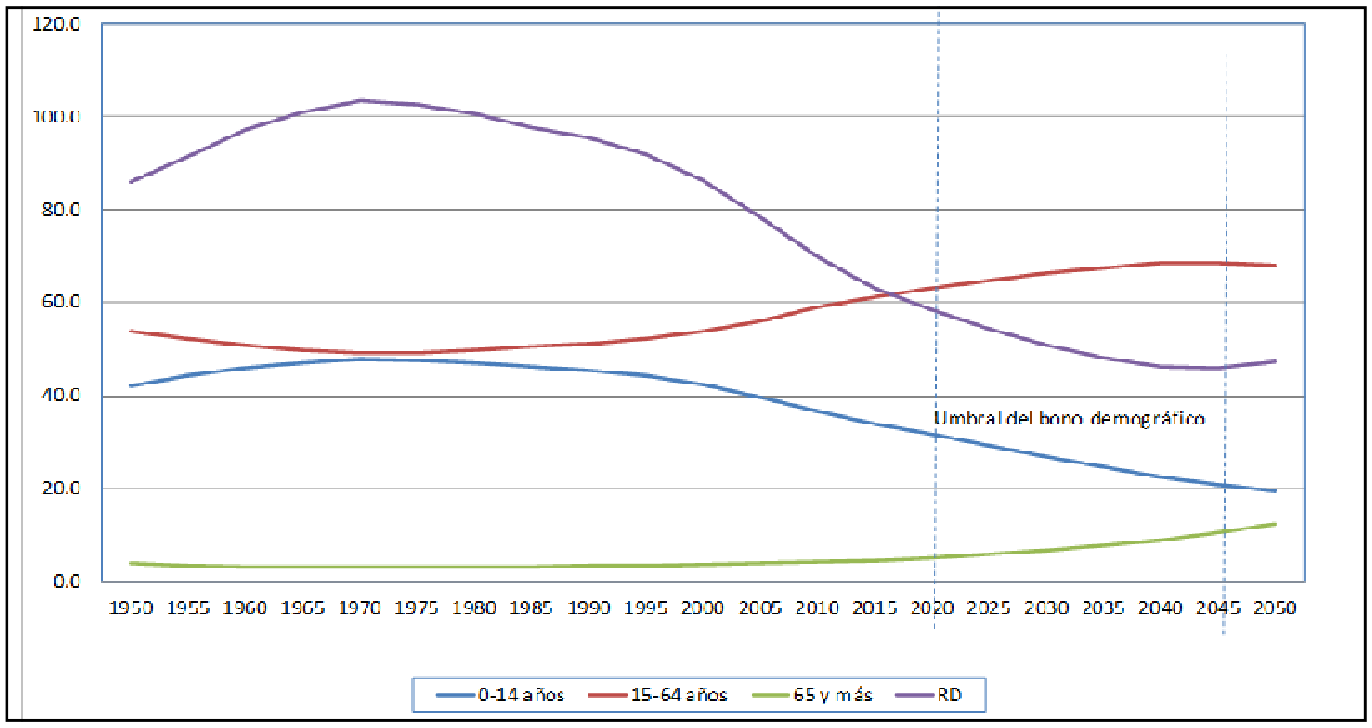

Gráfico 5, Honduras: Bono Demográfico.

(Fuente: Elaboración propia en base a datos de CELADE)

\subsection{Población objetivo de la Educación Terciaria.}

En la estructura demográfica de la población también hay otras poblaciones objetivo en varios sectores de la sociedad, tal es el caso de la educación y la salud.

En la educación resulta interesante el comportamiento de la población en edad de estudiar, aquellas donde el estudiante debería estarse educando, en la población de 5 a 6 años debería estar en preescolar, de 7 a 12 o de 7 a 15 años la población debería estar en la educación primaria o básica, en las edades de 13 a 
17 u 18 años estarían en la secundaria, de 16 a 17 u 18 años en la educación secundaria formativa y de 18 a 24 años debería estar en la educación universitaria o terciaria.

Es de nuestro interés enfocarnos en la educación en edad de estudiar en el nivel superior o terciario, es decir población de 18 a 24 años, donde en teoría las personas deben de estar estudiando en ese nivel de educación.

E\&A

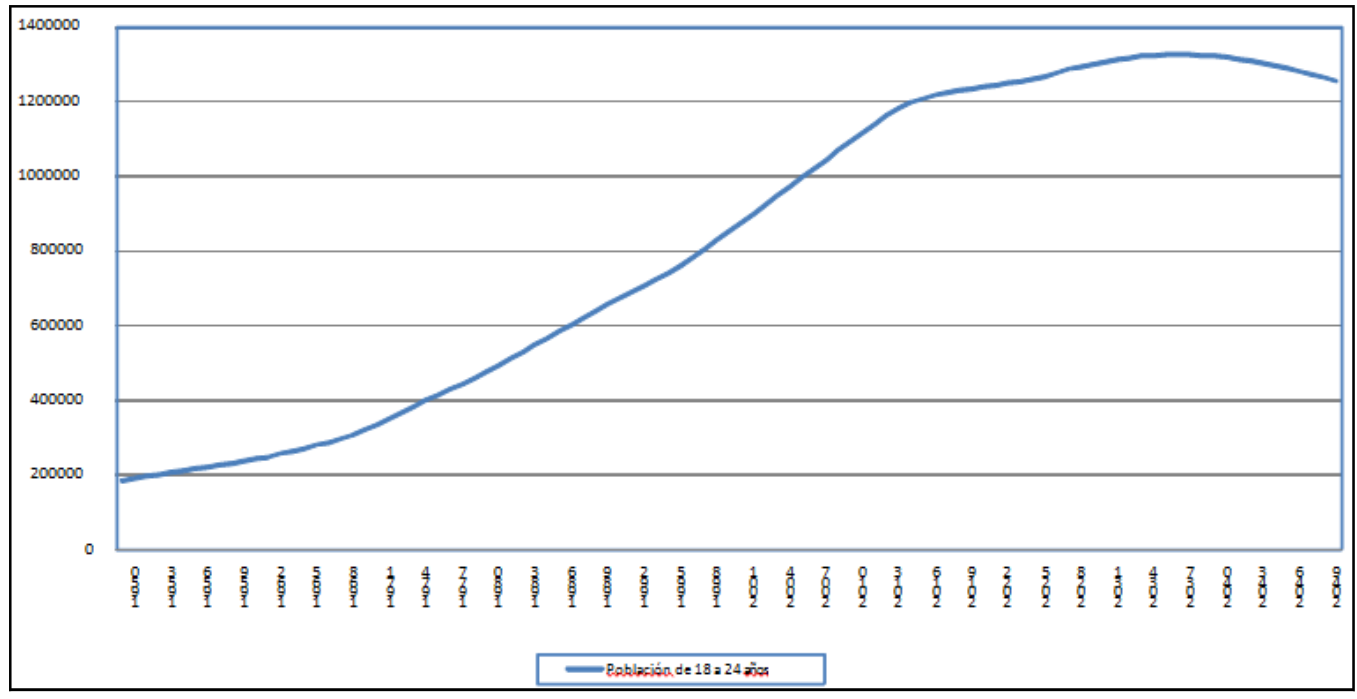

Gráfico 6, Honduras: Población en edad de educación Terciaria, 1950-2050

(Fuente: Elaboración propia en base a datos de CELADE)

La población en edad de estudiar en la educación terciaria tiene una tendencia incremental desde los años cincuenta hasta el año 2037 donde alcanzará su cúspide y emprender su descenso, por lo que el próximo cuarto de siglo los flujos de población en edad de estudiar en la educación superior serán los más grandes en historia demográfica hondureña (Gráfico No.6).

Aunque se vislumbre un panorama incremental en los próximos años, los porcentajes de este grupo poblacional del total de la población se sitúan en una franja que está entre el $11 \%$ y $14 \%$ del total, solamente en este último peso se mantendría entre el 2005 al 2017 (Gráfico No.7). 


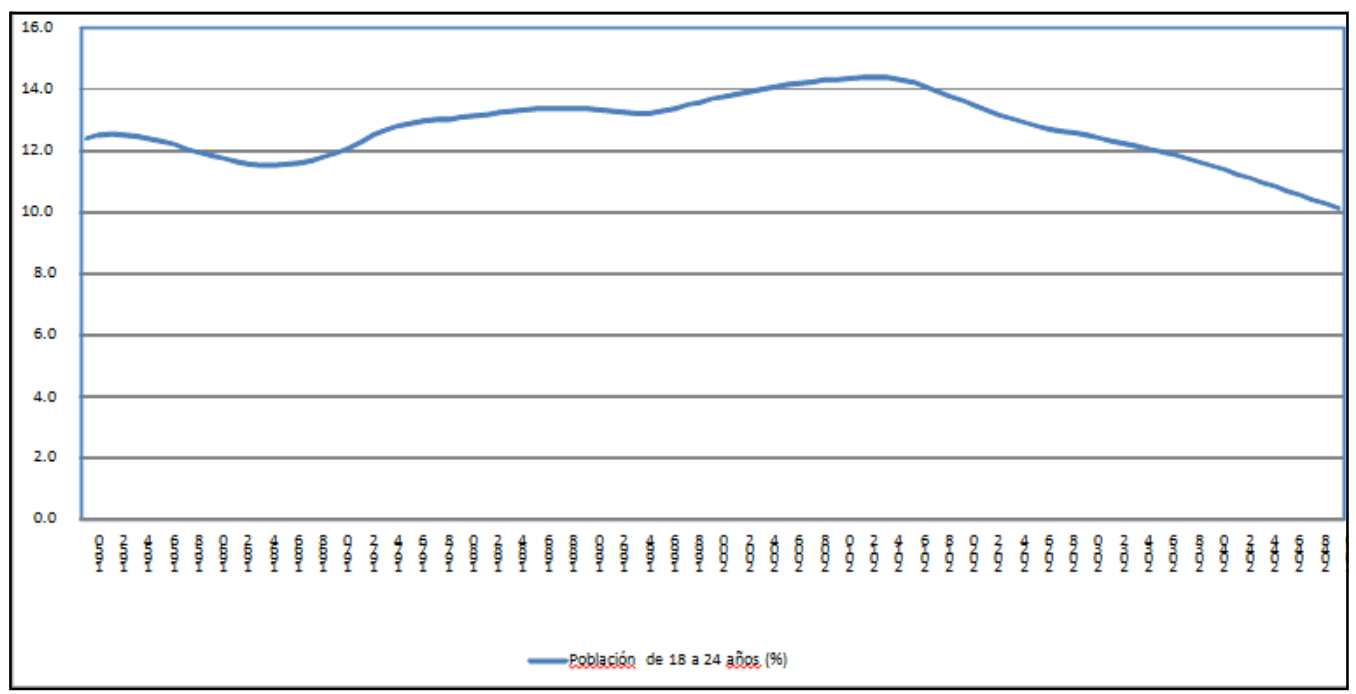

Gráfico 7, Honduras: Población en edad de educación terciaria, 1950-2050 $(\%)$

(Fuente: Elaboración propia en base a datos de CELADE)

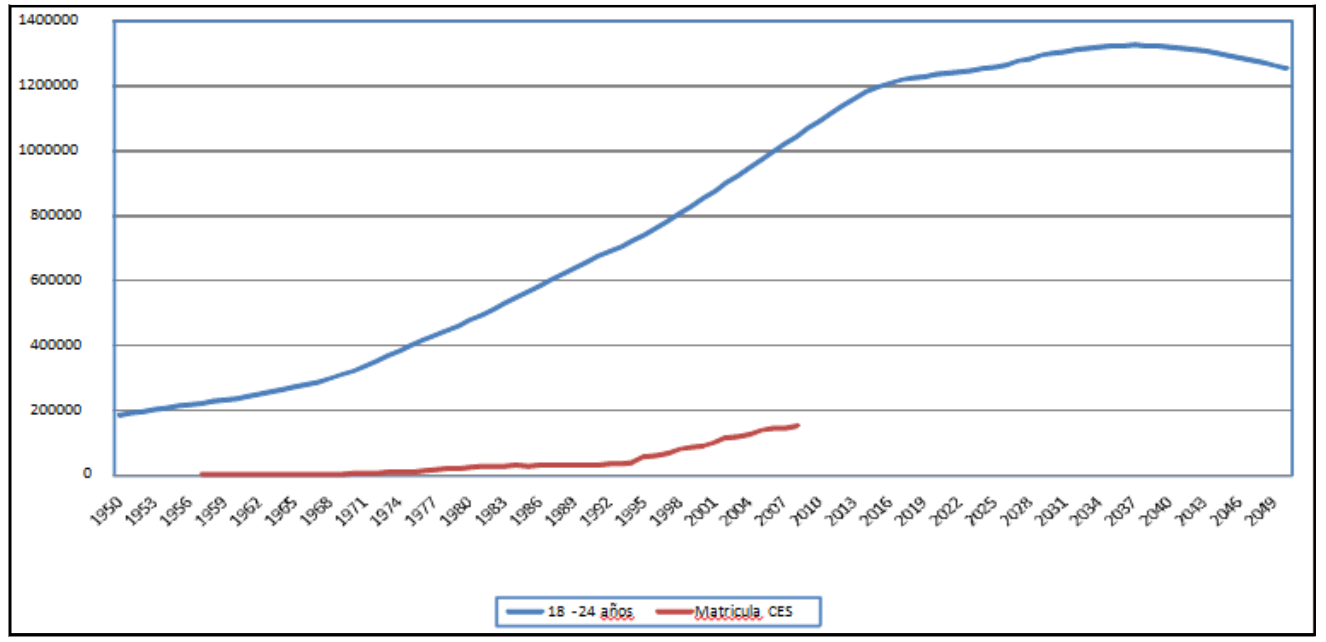

E\&A

IIES

Gráfico 8, Honduras: Población en edad de estudios terciarios y matrícula total CES, 1950-2050

(Fuente: Elaboración propia en base a datos de CELADE y Dirección de Educación Superior UNAH) 
La cobertura educativa superior en la población en el país es baja, alcanza el 15\% y su avance a través del tiempo ha sido lento, desde el año de 1997 que era de $7 \%$ transcurrieron 18 años para duplicarse y alcanzar el nivel actual. El incremento en la cobertura para el futuro depende de los flujos de entrada de la educación superior provenientes de la educación secundaria, de la posibilidad de tener acceso a la educación superior, de la oferta educativa y de las posibilidades económicas para continuar estudios (Gráfico No. 8).

\subsection{Poblaciones en las Redes Educativas Regionales de la UNAH.}

\subsubsection{Ubicación de las Redes Educativas de la UNAH.}

En el proceso de reforma universitaria que desarrolla en los últimos años la UNAH un punto central es la "gestión del conocimiento para facilitar los aprendizajes de los sujetos del proceso educativo para transformar la realidad". En ese cometido la UNAH adquiere un modelo de universidad no solo profesionalizante sino como agente de desarrollo, aportando desde su ámbito académico la ciencia, el arte y la cultura para resolver los problemas del país.

E\&A IIES

La construcción de redes regionalizadas para la gestión del conocimiento de la UNAH parte con base en la integración de varios criterios: la sede y cobertura actuales de los Centros Universitarios Regionales (CUR) y Centros Asociados Universitarios de Educación a Distancia (CASUED), las metas organizacionales del Plan General de la Reforma Integral, la visión de desarrollo regionalizado contenida en el Plan, ubicación de recursos naturales y cuencas, integración física y humana, regional y nacional; estructuras gubernamentales y políticas; concentración de niveles de pobreza, población estudiantil, estructuras 'productivas, demográficas; los recursos humanos, estructuras tecnológicas, científicas y financieras y las principales necesidades y potencialidades para el desarrollo (UNAH, 2008).

La regionalización propuesta de redes educativas de la UNAH es la siguiente: Red de la Región Tegucigalpa, Red de la Región del Norte, Red de la Región Central, Red de la Región Oriental, Red de la Región del Litoral Atlántico, Red de la Región Occidental, Red de la Región del Sur, Red de la región Sur Oriental (Figura No.1).

Red de la Región Tegucigalpa (UNAH-Tegucigalpa): comprende el departamento de Francisco Morazán y la parte alta de la región del Río Choluteca. 


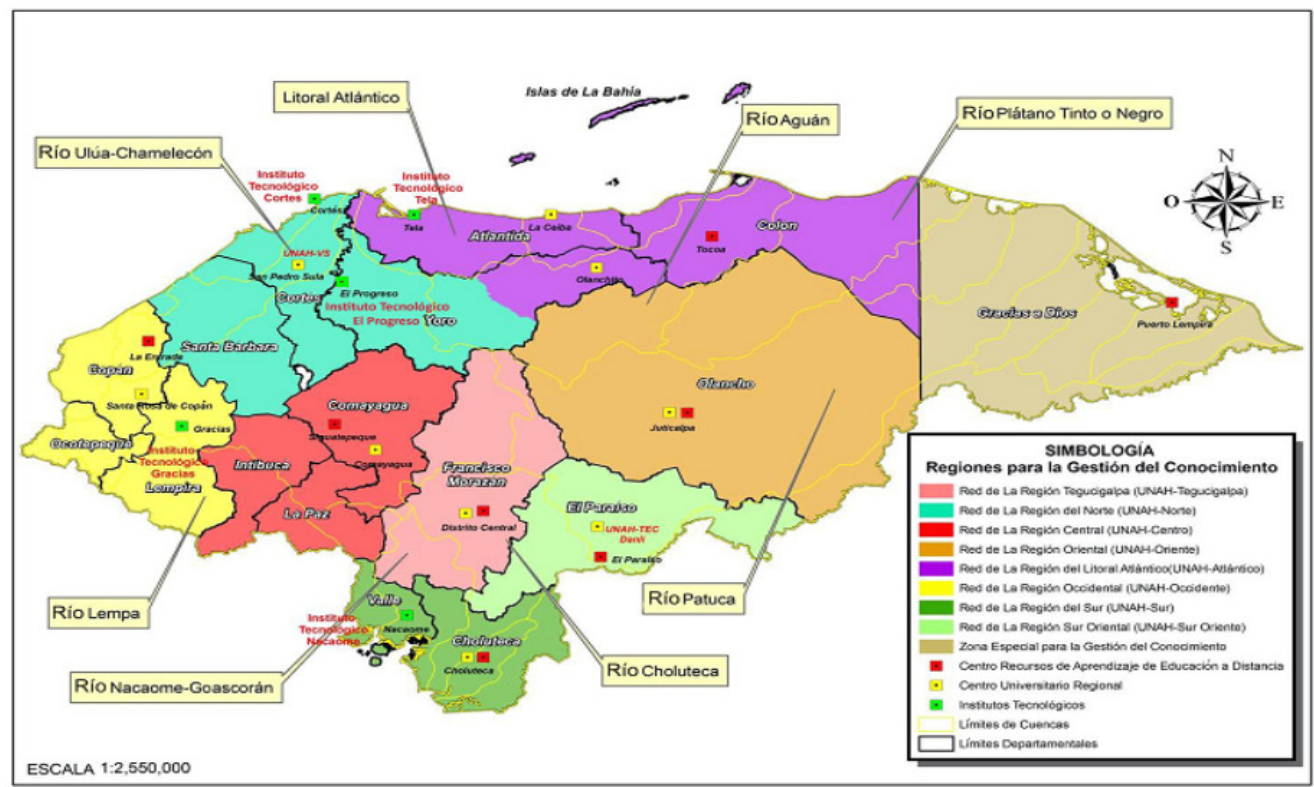

Figura 1, Redes educativas regionales de la UNAH para la gestión del conocimiento con calidad, pertinencia y equidad.

(Fuente: Publicaciones de la Reforma Universitaria No.2, UNAH)

La Red la constituye, inicialmente, Ciudad Universitaria con sede en Tegucigalpa, para los propósitos de la docencia con la modalidad a distancia, programas y proyectos de investigación, y de vinculación sociedad-universidad.

Red de la Región del Norte (UNAH-Norte): Conformada por los departamentos de Cortés y Santa Bárbara, y occidente de Yoro; integra la región del Río Chamelecón y del Río Ulúa.- La Red está constituida inicialmente por la UNAH en el Valle de Sula (UNAH-VS) con sede en San Pedro Sula, el CASUED de El Progreso y los futuros Institutos Tecnológicos de Puerto Cortés y de El Progreso.

Red de la Región Central (UNAH-Centro): Comprende los departamentos de Comayagua, La Paz e Intibucá, que integra la región del Río Chamelecón y del Río Ulúa; integrando inicialmente la Red, el Centro Universitario Regional del Centro (CURC) con sede en Comayagua, y el CASUED de Siguatepeque.

Red de la Región Oriental (UNAH-Oriente): Constituida por el departamento de Olancho; integra la región del alto Río Patuca y la red la constituyen, 
inicialmente, el Centro Universitario Regional Nororiental (CURNO) con sede en Juticalpa y el CASUED de Juticalpa.

Red de la Región del Litoral Atlántico (UNAH-Atlántico): Abarca los departamentos de Atlántida, Colón, Islas de la Bahía y oriente de Yoro; concentra la región del Litoral Atlántico, la región del Río Aguan y parte de la región del Río Plátano-Tinto o Negro.- La Red la integran, inicialmente, el Centro Universitario Regional del Litoral Atlántico (CURLA) con sede en La Ceiba, el Centro Universitario Regional del Valle del Aguan (CURVA) con sede en Olanchito, el CASUED de Tocoa, el Centro Experimental de Sinaloa, y el futuro Instituto Tecnológico de Tela.

Red de la Región Occidental (UNAH-Occidente): Engloba los departamentos de Copán, Ocotepeque y Lempira; integra la región del Río Chamelecón-Ulúa y Río Lempa.- La Red la constituyen inicialmente el Centro Universitario Regional de Occidente (CUROC) con sede en Santa Rosa de Copán y el CASUED de La Entrada, y el futuro CRAD o Instituto Tecnológico de Gracias.

$\mathbf{E \& A}$ IIES

Red de la Región del Sur (UNAH-Sur): Conformada por los departamentos de Choluteca y Valle; integrando la parte baja de la región del Río Choluteca y Río Nacaome-Goascorán.- La Red inicialmente la conforman el Centro Universitario Regional del Litoral Pacífico (CURLP) con sede en Choluteca, el CASUED de Choluteca, y el futuro Instituto Tecnológico de Nacaome.

Red de la Región Sur Oriental (UNAH-Sur Oriente): Conformada por el departamento de El Paraíso; integrando la parte baja región del Río Patuca.- La Red la conforman inicialmente UNAH-TEC-Danlí con sede en la ciudad de Danlí y el CASUED de El Paraíso.

En el caso del Departamento de Gracias a Dios, por sus condiciones y características propias, se define como una zona especial.

\subsubsection{Tamaño y ritmo de la Población en las Redes Edu cativas de la UNAH.}

La Norte y Tegucigalpa se convierten en las regiones donde hay un mayor volumen de población, ambas tienen actualmente el $48 \%$ de la población del país. La región norte tiene el mayor número de efectivos ya que en ella se 
ubica el segundo y tercer municipios más poblados del país, San Pedro Sula y Choloma y se suma a ello una serie de municipios que albergan ciudades intermedias como Villanueva, El Progreso y Puerto Cortés.

Las regiones Centro, Atlántico, Occidente y Sur tienen poblaciones muy similares en volumen, alrededor de los 400 a 460 mil personas, mismas que pueden ser un segmento de regiones de poblaciones similares, lo mismo pasa con la región Oriente y Sur Oriente, con poblaciones alrededor de los 250 mil personas y por último la región especial que tiene una escasa población.

\section{Tabla No.1}

Honduras: Población Total por año según Redes Educativas de la UNAH, 1988 $-2015$

\begin{tabular}{|l|l|r|r|r|r|}
\hline \multicolumn{1}{|c|}{ Número } & \multicolumn{1}{|c|}{ Región } & \multicolumn{1}{c|}{1988} & \multicolumn{1}{c|}{2001} & \multicolumn{1}{c|}{2011} & \multicolumn{1}{c|}{2015} \\
\hline Región I & Tegucigalpa & 781,601 & $1,109,900$ & $1,460,429$ & $1,562,460$ \\
\hline Región II & Norte & $1,150,962$ & $1,754,081$ & $2,471,162$ & $2,691,852$ \\
\hline Región III & Centro & 451,838 & 655,208 & 892,938 & 983,906 \\
\hline Región IV & Oriente & 272,772 & 384,881 & 520,053 & 562,868 \\
\hline Región V & Atlántico & 461,526 & 656,060 & 874,218 & 932,787 \\
\hline Región VI & Occidente & 452,778 & 622,230 & 828,493 & 904,305 \\
\hline Región VII & Sur & 399,034 & 506,495 & 641,029 & 682,890 \\
\hline Región VIII & Sur Oriente & 244,366 & 331,351 & 436,138 & 472,450 \\
\hline Zona Es pecial & La Mosquitia & 33,684 & 56,679 & 90,853 & 101,457 \\
\hline & Total & $4,248,561$ & $6,076,885$ & $8,215,313$ & $8,894,975$ \\
\hline
\end{tabular}

Fuente: Cálculos propios en base a datos de CNPV 1988 y 2001 y Proyecciones de Población, INE.

En la última década todas las regiones educativas incrementaron sus efectivos con tasas de crecimiento demográfico entre los 2.4 a 4.7, tasas consideradas poblacionalmente elevadas. Es sorprendente la tasa de la región norte, que además es la más poblada del país. Para el futuro cercano entre el 2011 al 2015 las tasas de crecimiento serán menores, aunque la región centro superará a la norte en este indicador.

Las poblaciones diferenciadas por sexo nos indican una leve supremacía en la población femenina. En las regiones de Tegucigalpa y Norte tienen los índices de masculinidad menores, producto de que las regiones más urbanizadas hay una proporción de mujeres más alta que las rurales. 
Tabla No.2

Honduras: Tasas de Crecimiento de la Población Total según Redes Educativas de la UNAH, 1988-2015

\begin{tabular}{|l|l|r|r|r|}
\hline \multicolumn{1}{|c|}{ Número } & \multicolumn{1}{c|}{ Región } & 1988-2001 & 2001-2011 & 2011-2015 \\
\hline Región I & Tegucigalpa & 2.66 & 2.74 & 1.69 \\
\hline Región II & Norte & 3.20 & 3.43 & 2.14 \\
\hline Región III & Centro & 2.82 & 3.10 & 2.43 \\
\hline Región IV & Oriente & 2.62 & 3.01 & 1.98 \\
\hline Región V & Atlántico & 2.67 & 2.87 & 1.62 \\
\hline Región VI & Occidente & 2.41 & 2.86 & 2.19 \\
\hline Región VII & Sur & 1.81 & 2.36 & 1.58 \\
\hline Región VIII & Sur Oriente & 2.31 & 2.75 & 2.00 \\
\hline Zona Especial & La Mosquitia & 3.95 & 4.72 & 2.76 \\
\hline & Total & 2.72 & 3.02 & 1.99 \\
\hline
\end{tabular}

Fuente: Cálculos propios en base a datos de CNPV 1988 y 2001 y Proyecciones de Población, INE.

Tabla No.3

Honduras: Índice de Masculinidad por año según Redes Educativas UNAH, $1988-2015$

\begin{tabular}{|l|l|r|r|r|r|}
\hline \multicolumn{1}{|c|}{ Número } & \multicolumn{1}{c|}{ Región } & \multicolumn{1}{c|}{ IM 1988 } & IM 2001 & IM 2011 & \multicolumn{1}{c|}{ IM 2015 } \\
\hline Región I & Tegucigalpa & 91.99 & 93.00 & 93.05 & 93.06 \\
\hline Región II & Norte & 99.46 & 97.78 & 96.46 & 96.21 \\
\hline Región III & Centro & 100.10 & 98.95 & 97.50 & 97.22 \\
\hline Región IV & Oriente & 102.92 & 101.30 & 100.14 & 99.95 \\
\hline Región V & Atlántico & 100.99 & 98.61 & 97.38 & 97.15 \\
\hline Región VI & Occidente & 101.14 & 102.14 & 101.17 & 101.10 \\
\hline Región VII & Sur & 99.09 & 98.71 & 98.32 & 98.38 \\
\hline Región VIII & Sur Oriente & 101.16 & 102.36 & 100.71 & 100.36 \\
\hline Zona Especial & La Mosquitia & 93.20 & 96.49 & 98.60 & 99.38 \\
\hline & Total & 98.67 & 98.07 & 97.13 & 96.99 \\
\hline
\end{tabular}

Fuente: Cálculos propios en base a datos de CNPV 1988 y 2001 y Proyecciones de Población, INE. 


\subsection{3. Área de Residencia y Migración Interna en las Redes Educativas de la UNAH.}

La población según área de residencia es muestra palpable de la urbanización hondureña, si bien es uno de los países en la región donde el proceso de urbanización ha sido más lento, donde recién hace pocos años se ha sobrepasado a la población viviendo en área urbanas.

Tabla No.4

Honduras: Población por área de residencia según Redes Educativas UNAH, 2011-2015

\begin{tabular}{|l|l|r|r|r|r|r|r|}
\hline & & \multicolumn{3}{|c|}{2011} & & \multicolumn{2}{c|}{2015} \\
\cline { 3 - 8 } \multicolumn{1}{c|}{ Número } & \multicolumn{1}{c|}{ Región } & urbano & Rural & Total & urbano & rural & Total \\
\hline Región I & Tegucigalpa & 78.6 & 21.4 & 100.0 & 79.5 & 20.5 & 100.0 \\
\hline Región II & Norte & 68.4 & 31.6 & 100.0 & 71.2 & 28.8 & 100.0 \\
\hline Región III & Centro & 27.9 & 72.1 & 100.0 & 27.7 & 72.3 & 100.0 \\
\hline Región IV & Oriente & 30.2 & 69.8 & 100.0 & 31.8 & 68.2 & 100.0 \\
\hline Región V & Atlántico & 53.5 & 46.5 & 100.0 & 56.5 & 43.5 & 100.0 \\
\hline Región VI & Occidente & 22.0 & 78.0 & 100.0 & 23.9 & 76.1 & 100.0 \\
\hline Región VII & Sur & 34.0 & 66.0 & 100.0 & 35.9 & 64.1 & 100.0 \\
\hline Región VIII & Sur Oriente & 28.1 & 71.9 & 100.0 & 29.3 & 70.7 & 100.0 \\
\hline Zona Especial & La Mosquitia & 22.0 & 78.0 & 100.0 & 23.6 & 76.4 & 100.0 \\
\hline & Total & 51.8 & 48.2 & 100.0 & 53.5 & 46.5 & 100.0 \\
\hline
\end{tabular}

Fuente: Cálculos propios en Base a Proyecciones de Población, INE.

Las regiones de Tegucigalpa, Norte y Atlántico son las únicas que sobrepasan el promedio nacional actualmente. Las demás regiones privan una ruralidad grande que no supera el tercio del total, a lo cual desde el punto de vista educativo la estrategia de ampliación de cobertura debe de tener en cuenta. Para el futuro cercano aunque se incrementará la urbanización a nivel de regiones educativas no se esperan cambios espectaculares.

Las regiones Norte, Tegucigalpa y Atlántico son las muestran saldos migratorios internos positivos de toda la vida a nivel de División Administrativa Menor (DAME), en otras palabras son aquellas que son atractivas desde el punto de vista migratorio para trasladarse a residir a municipios en esas regiones, que además tienen municipios y ciudades altamente atractivos como San Pedro Sula, Tegucigalpa, Choloma, Villanueva, Puerto Cortés, La Lima, San Manuel, El Progreso, Santa Cruz de Yojoa y La Ceiba (Gráfico No.9). 


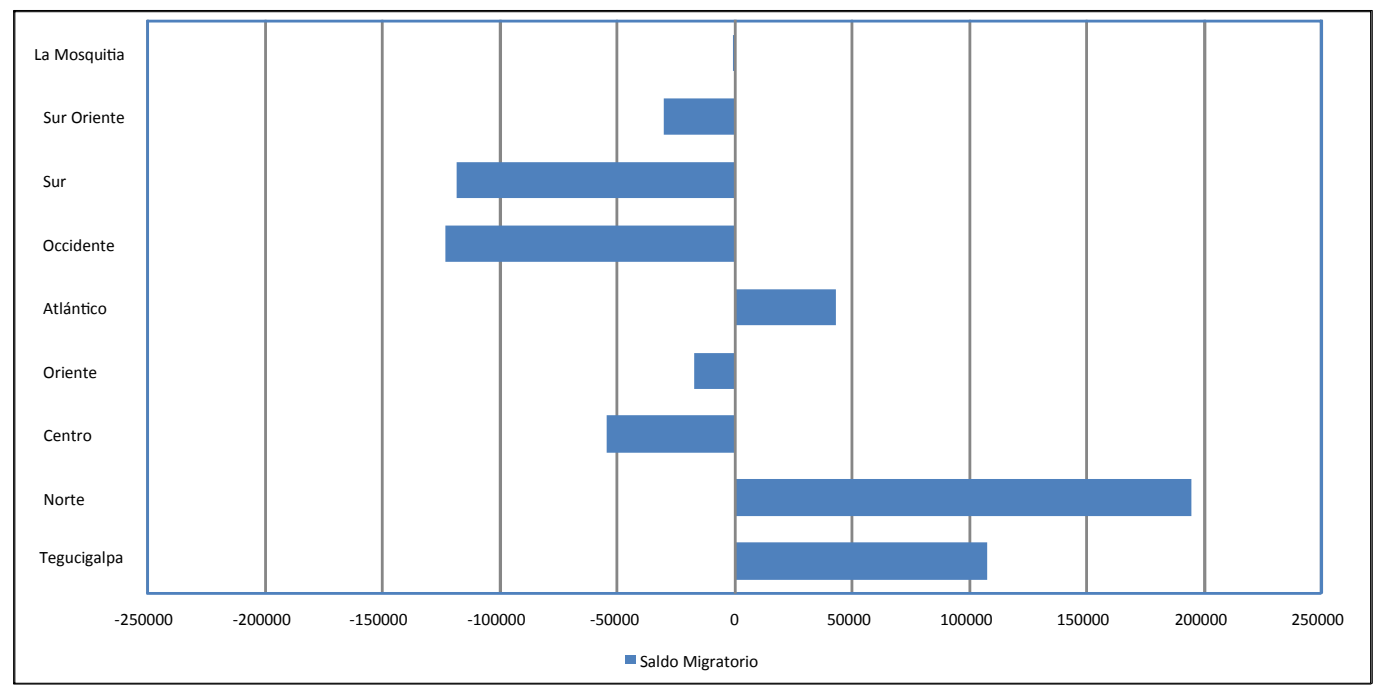

Gráfico 9, Honduras: Saldos migratorios de toda la vida por redes educativas UNAH, 2011.

(Fuente: Elaboración propia de base censal 2001, INE)

E\&A

IIES

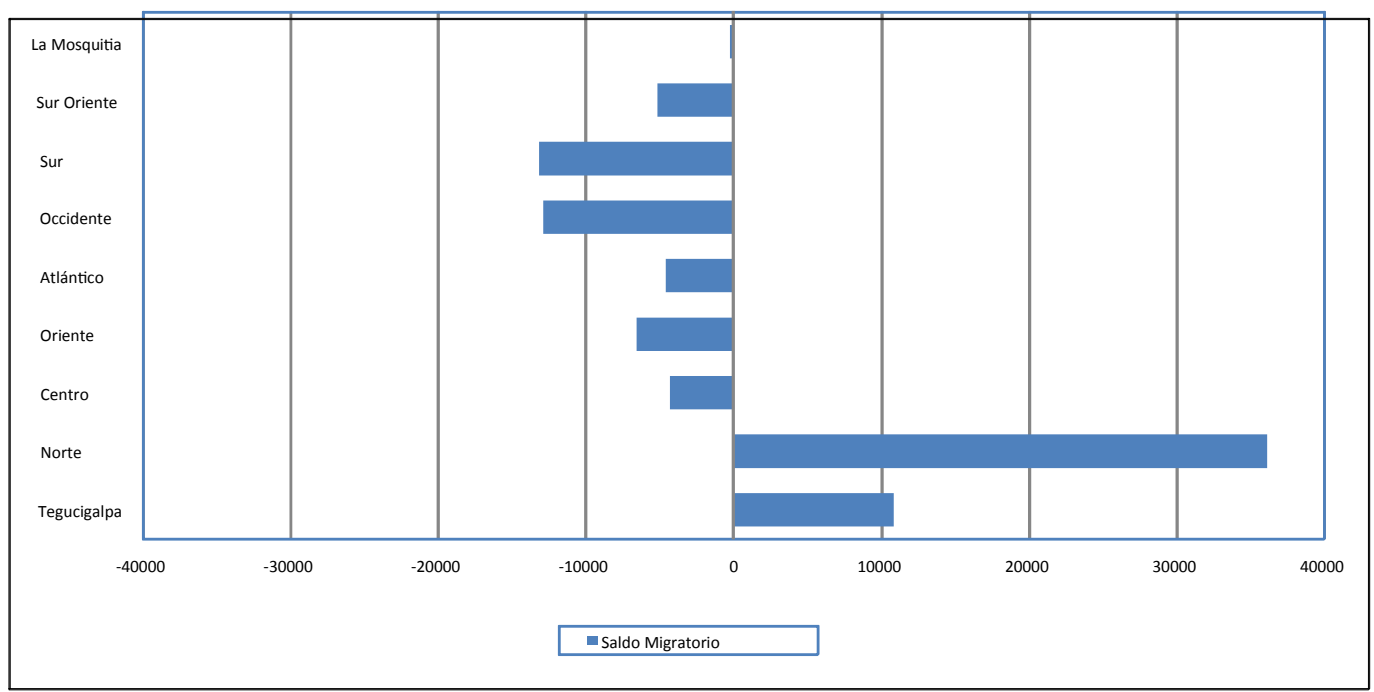

Gráfico 10, Honduras: Saldo migratorio reciente por redes educativas de la UNAH, 1996-2001

(Fuente: Elaboración propia de base censal 2001, INE) 
En el caso de la migración reciente (1996-2001) se observa una mayor concentración de los migrantes en la región Note y Tegucigalpa (Gráfico No.10). Los municipios con mayor saldo migratorio positivo reciente fueron Villanueva y Choloma que superaron en la primacía a Tegucigalpa y San Pedro Sula y se convirtieron en los últimas dos décadas en municipios altamente atractivos por la creciente generación de empleo en maquilas. Los municipios de mayor saldo migratorio negativo reciente incluye una mayor diversificación, a excepción de Tela en la región Atlántico y Pespire, El Triunfo, Langue y Concepción de María en la región sur del país que tienen una larga tradición de perder poblaciones por emigración (Flores, 2005).

\subsubsection{Población en Edad de Educación Terciaria en las Redes Educativas de la UNAH.}

La población objetivo en edad de educación terciaria comprende el grupo de edades entre los 18 a 24 años de edad. En el caso de Honduras podemos observar con los datos de los dos últimos censos y de la proyección de población como esta ha tenido un aumento en el número de efectivos, de medio millón de personas en 1988 ha pasado a duplicarse actualmente y continuará aumentando en el futuro.

\section{Tabla No.5}

E\&A

IIES

75

Honduras: Población en Edad de Educación Terciaria por año según Redes Educativas de la UNAH (18 - 24 años)

\begin{tabular}{|l|l|r|r|r|r|}
\hline Número & \multicolumn{1}{|c|}{ Región } & \multicolumn{1}{c|}{1988} & \multicolumn{1}{c|}{2001} & \multicolumn{1}{c|}{2011} & \multicolumn{1}{c|}{2015} \\
\hline Región I & Tegucigalpa & 110,567 & 170,548 & 187,190 & 198,399 \\
\hline Región II & Norte & 141,944 & 267,866 & 320,410 & 361,024 \\
\hline Región III & Centro & 50,052 & 88,008 & 122,210 & 137,776 \\
\hline Región IV & Oriente & 30,620 & 51,505 & 74,423 & 81,567 \\
\hline Región V & Atlántico & 52,851 & 87,291 & 123,175 & 133,262 \\
\hline Región VI & Occidente & 49,133 & 81,158 & 111,206 & 124,208 \\
\hline Región VII & Sur & 42,583 & 64,327 & 92,319 & 98,303 \\
\hline Región VII & Sur Oriente & 27,764 & 44,349 & 59,692 & 66,582 \\
\hline Zona Espe & La Mosquiti: & 4,157 & 7,143 & 13,101 & 15,191 \\
\hline & Total & 509,671 & 862,195 & $1,103,726$ & $1,216,312$ \\
\hline
\end{tabular}

Fuente: Cálculos propios con datos de CNPV 1988 y 2001 y Proyecciones de Población, INE. 
La región Norte tiene supremacía en poblaciones en edad de educación terciaria, misma que ha aumentado y seguirá en esa tendencia a través del tiempo, actualmente representa el 29\% del total en esta sub población. En segundo lugar se encuentra la región Tegucigalpa, más por el volumen de la Ciudad Capital. Las regiones de Centro, Atlántico y Occidente pueden considerarse con volúmenes similares en esta sub población.

\section{Tabla No.6}

Honduras: Tasas de Crecimiento de la Población Total según Redes Educativas de la UNAH, 1988-2015

E\&A

\begin{tabular}{|l|l|r|r|r|}
\hline \multicolumn{1}{|c|}{ Número } & \multicolumn{1}{c|}{ Región } & 1988-2001 & 2001-2011 & 2011-2015 \\
\hline Región I & Tegucigalpa & 3.29 & 0.93 & 1.45 \\
\hline Región II & Norte & 4.82 & 1.79 & 2.98 \\
\hline Región III & Centro & 4.29 & 3.28 & 3.00 \\
\hline Región IV & Oriente & 3.95 & 3.68 & 2.29 \\
\hline Región V & Atlántico & 3.81 & 3.44 & 1.97 \\
\hline Región VI & Occidente & 3.81 & 3.15 & 2.76 \\
\hline Región VII & Sur & 3.13 & 3.61 & 1.57 \\
\hline Región VIII & Sur Oriente & 3.56 & 2.97 & 2.73 \\
\hline Zona Especial & La Mosquitia & 4.11 & 6.07 & 3.70 \\
\hline & Total & 3.99 & 2.47 & 2.43 \\
\hline
\end{tabular}

Fuente: Cálculos propios con datos de CNPV 1988 y 2001 y Proyecciones de Población, INE.

Las poblaciones objetivo de educación terciaria en la última década y los próximos años disminuirá levemente su crecimiento. Sin embargo, para los próximos cuatro años las regiones Centro, Norte, Sur Oriente, La Mosquitia y Occidente crecerán a una tasa mayor del promedio nacional en este grupo de edad.

En la sub población de 18 a 24 años de edad los índices de masculinidad actualmente son superiores a cien en cinco regiones educativas, es decir hay más hombres que mujeres, principalmente en la región Oriente, Occidente y Sur. Para el 2015 solo tres regiones tendrán más mujeres que hombres y que son altamente urbanizadas (Norte y Tegucigalpa), la región Centro es una excepción. 


\section{Tabla No.7}

Honduras: Índice de Masculinidad de Población en Edad de Educación Terciaria según Redes Educativas UNAH, 1988-2015

\begin{tabular}{|l|l|r|r|r|r|}
\hline \multicolumn{1}{|c|}{ Número } & \multicolumn{1}{|c|}{ Región } & IM 1988 & IM 2001 & IM 2011 & IM 2015 \\
\hline Región I & Tegucigalpa & 83.05 & 89.77 & 95.68 & 97.54 \\
\hline Región II & Norte & 89.97 & 91.15 & 96.78 & 98.08 \\
\hline Región III & Centro & 92.51 & 96.10 & 99.69 & 98.27 \\
\hline Región IV & Oriente & 101.98 & 99.07 & 104.11 & 104.49 \\
\hline Región V & Atlántico & 91.32 & 94.90 & 101.10 & 101.92 \\
\hline Región VI & Occidente & 95.85 & 103.56 & 104.21 & 102.67 \\
\hline Región VII & Sur & 93.78 & 95.60 & 103.77 & 102.41 \\
\hline Región VIII & Sur Oriente & 95.76 & 99.58 & 102.69 & 101.87 \\
\hline Zona Especial & La Mosquitia & 77.88 & 88.87 & 95.45 & 101.07 \\
\hline & Total & 90.54 & 94.05 & 99.47 & 99.90 \\
\hline
\end{tabular}

Fuente: Cálculos propios con datos de CNPV 1988 y 2001 y Proyecciones de Población, INE.

\subsubsection{Población Total y en Edad de Educación Terciaria dentro de las Redes Educativas de la UNAH.}

E\&A

IIES

Dentro de las redes hay municipios que tienen un mayor número de población y de poblaciones objetivo de la educación terciaria. Estos pueden ser considerados los municipios que deberían tener los mayores aportantes de la educación superior en Honduras. Estos veinticinco municipios tienen alrededor del 55\% de la población total y de la población objetivo de la educación superior del país. 


\section{Tabla No.8}

Honduras: Veinticinco Municipios con Mayor Población actual, 2011-2015

\begin{tabular}{|l|r|r|r|r|r|r|r|r|}
\hline & \multicolumn{2}{|c|}{2011} & \multicolumn{2}{c|}{2015} & \multicolumn{2}{|c|}{2011} & \multicolumn{2}{|c|}{2015} \\
\cline { 2 - 10 } Municipios & $\begin{array}{c}\text { Población } \\
\text { Total }\end{array}$ & $\begin{array}{c}18-24 \\
\text { años }\end{array}$ & $\begin{array}{c}\text { Población } \\
\text { total }\end{array}$ & $\begin{array}{c}18-24 \\
\text { años }\end{array}$ & $\begin{array}{l}\text { Pob. } \\
\text { Total }\end{array}$ & $\begin{array}{c}18-24 \\
\text { años }\end{array}$ & $\begin{array}{l}\text { Pob. } \\
\text { total }\end{array}$ & $\begin{array}{c}18-24 \\
\text { años }\end{array}$ \\
\hline IISTRITO CENTRAL & $1,149,923$ & 152,263 & $1,239,557$ & 162,428 & 14.00 & 13.80 & 13.94 & 13.35 \\
\hline SAN PEDRO SULA & 731,762 & 93,159 & 772,472 & 101,273 & 8.91 & 8.44 & 8.68 & 8.33 \\
\hline CHOLOMA & 290,876 & 43,442 & 350,602 & 54,834 & 3.54 & 3.94 & 3.94 & 4.51 \\
\hline EL PROGRESO & 210,507 & 34,620 & 236,033 & 39,053 & 2.56 & 3.14 & 2.65 & 3.21 \\
\hline LA CEIBA & 191,160 & 28,909 & 212,458 & 27,471 & 2.33 & 2.62 & 2.39 & 2.26 \\
\hline DANLI & 185,604 & 26,409 & 203,512 & 29,694 & 2.26 & 2.39 & 2.29 & 2.44 \\
\hline CHOLUTECA & 174,039 & 26,775 & 193,230 & 29,950 & 2.12 & 2.43 & 2.17 & 2.46 \\
\hline VILLANUEVA & 143,471 & 16,705 & 167,309 & 20,591 & 1.75 & 1.51 & 1.88 & 1.69 \\
\hline JUT ICALPA & 122,738 & 19,686 & 136,099 & 21,778 & 1.49 & 1.78 & 1.53 & 1.79 \\
\hline COMAYAGUA & 121,257 & 17,964 & 132,659 & 19,914 & 1.48 & 1.63 & 1.49 & 1.64 \\
\hline PUERTO CORTES & 116,183 & 12,011 & 118,845 & 12,781 & 1.41 & 1.09 & 1.34 & 1.05 \\
\hline CAT ACAMAS & 116,104 & 16,943 & 129,288 & 18,902 & 1.41 & 1.54 & 1.45 & 1.55 \\
\hline OLANCHITO & 97,287 & 12,298 & 102,544 & 13,489 & 1.18 & 1.11 & 1.15 & 1.11 \\
\hline TELA & 87,719 & 11,497 & 87,371 & 13,733 & 1.07 & 1.04 & 0.98 & 1.13 \\
\hline SIGUATEPEQUE & 87,718 & 12,469 & 98,015 & 14,136 & 1.07 & 1.13 & 1.10 & 1.16 \\
\hline TOCOA & 82,798 & 13,288 & 89,182 & 13,992 & 1.01 & 1.20 & 1.00 & 1.15 \\
\hline SANTA CRUZDE YOJOA & 81,237 & 7,161 & 87,097 & 8,245 & 0.99 & 0.65 & 0.98 & 0.68 \\
\hline YORO & 79,776 & 10,238 & 83,300 & 11,277 & 0.97 & 0.93 & 0.94 & 0.93 \\
\hline LA LIMA & 63,302 & 7,405 & 63,090 & 7,631 & 0.77 & 0.67 & 0.71 & 0.63 \\
\hline NACAOME & 59,512 & 9,100 & 63,791 & 9,410 & 0.72 & 0.82 & 0.72 & 0.77 \\
\hline STA. ROSA DE COPAN & 58,066 & 8,951 & 66,134 & 9,849 & 0.71 & 0.81 & 0.74 & 0.81 \\
\hline TRUJILLO & 57,926 & 8,992 & 62,039 & 9,955 & 0.71 & 0.81 & 0.70 & 0.82 \\
\hline SAN MANUEL & 56,431 & 5,809 & 70,467 & 7,679 & 0.69 & 0.53 & 0.79 & 0.63 \\
\hline INTIBUCA & 56,105 & 8,337 & 63,600 & 9,806 & 0.68 & 0.76 & 0.72 & 0.81 \\
\hline GRACIAS & 52,068 & 8,021 & 61,835 & 9,637 & 0.63 & 0.73 & 0.70 & 0.79 \\
\hline
\end{tabular}

Fuente: Cálculos propios con datos de CNPV 2001 y Proyecciones de Población, INE. 


\section{CONCLUSIÓN}

El comportamiento de la dinámica demográfica hondureña está inmersa en la teoría de la transición demográfica, donde la conjugación de los descensos de la mortalidad y fecundidad en forma no sincronizada han llevado al crecimiento acelerado de la población manifestado en aumento en el volumen de la población que culminará hasta el último cuarto del presente siglo, como también en transformaciones en la estructura por edad de la población que llevará número elevados de la población en edad de trabajar como nunca en la historia y a cambios en relaciones de dependencia demográfica que caerá a niveles bajos que produce en un periodo de varios años de una situación demográfica favorable para el crecimiento económico.

Los cambios demográficos que también se producen en grupos especiales, tanto de la salud y la educación, llevará a cambiar el flujo de recursos financieros a grupos prioritarios, que no necesariamente son los mismos que se priorizan actualmente. Dentro de los grupos especiales en educación, está la población en edad de educación terciaria que alcanzará un número efectivos teóricos elevados en las próximas décadas que demandarán los servicios de educación. La cobertura educativa superior en el país es baja (15\%) y su incremento para el futuro depende de los flujos de entrada del nivel educativo anterior, de la posibilidad de tener acceso, de la oferta educativa y de las posibilidades económicas para continuar estudios. Por redes educativas de la UNAH la Norte tiene supremacía en poblaciones en edad de educación terciaria, misma que ha aumentado y seguirá en esa tendencia a través del tiempo, actualmente representa el 29\%. En segundo lugar se encuentra la red Tegucigalpa. Las redes del Centro, Atlántico y Occidente pueden considerarse con volúmenes similares. Hay 25 municipios que representan alrededor del 55\% de la población y de poblaciones objetivo de la educación terciaria.

\section{RECONOCIMIENTOS}

Esta investigación ha sido financiada parcialmente por el Consejo Nacional de Educación de Honduras, la Beca Sustantiva de Investigación No. 03-2011 por parte de la Dirección de Investigación Científica y por la Vice-rectoría académica de la UNAH. El autor desea agradecer el apoyo del Gobierno de Honduras y de la UNAH. 


\section{REFERENCIAS}

Baumeister, Eduardo (2010). Bases estructurales de la emigración internacional de los hondureños, Tegucigalpa, Red de Desarrollo Sostenible de Honduras, RDS-HN.

CELADE (2005). Dinámica demográfica y desarrollo en América Latina y el Caribe, serie Población y Desarrollo \# 58, Santiago, CELADE.

Ennis, Sharon R. y otros (2011). The hispanic population: 2010, Washington, U.S. Census Bureau.

Flores, Manuel (2005). Migración interna intermunicipal de Honduras, Tegucigalpa, Instituto de Investigaciones Económicas y Sociales (IIES), Universidad Nacional Autónoma de Honduras (UNAH).

Flores, Manuel (2007). La Transición Demográfica de Honduras, Tegucigalpa, Fondo de Población de las Naciones Unidas (UNFPA).

Flores, Manuel (2009). La Medición Censal de la Migración, Notas de Población No. 88 (LC/G.2409-P), Santiago de Chile, Comisión Económica Para América Latina y El Caribe (CEPAL)/Centro Latinoamericano de Demografía (CELADE).

INE (2006). Encuesta Nacional de Demografía y Salud 2005-2006, Informe Familiar, Tegucigalpa, Instituto Nacional de Estadística de Honduras (INE).

INE (2011). Avance del Padrón al 1 de enero del 2011, Datos provisionales. Madrid, Instituto Nacional de Estadística de España (INE).

Pew Hispanic Center (2011). Statistical Profile Hispanics of Honduran Origin in the United States, Washington, Pew Hispanic Center.

Ratha, Dilip, Mohapatra, Sanket y Silwal, Ani (2011). Datos sobre migración y remesas 2011, Washington, Grupo del Banco Mundial.

UNAH, (2008). Redes Educativas Regionales de la UNAH para la Gestión del Conocimiento con Calidad, Pertinencia y Equidad, Serie de Publicaciones de la Reforma Universitaria No.2, Tegucigalpa, UNAH. 